\title{
Vibriocidal Activity of Selected Medicinal Plants Used by Nicobarese Tribe of Andaman and Nicobar Islands, India
}

\author{
Manda Punnam Chander and Paluru Vijayachari \\ Regional Medical Research Centre (ICMR), WHO Collaborating Centre for Diagnosis, Reference, Research and Training in \\ Leptospirosis, Andaman and Nicobar Islands 744101, India
}

\begin{abstract}
The aim of the study was to investigate the vibriocidal activity of crude extracts of 18 ethnomedicinal plants used by Nicobarese tribe. Plants were collected from the villages of Car Nicobar Island with the help of TKPs (traditional knowledge practitioners). The methanol extracts were obtained by cold percolation method and the antimicrobial activity of the extracts was observed by agar well diffusion method. Results indicated that out of 18 plants, seven plants exhibited vibriocidal activity. Morinda citrifolia, Ganophyllum falcatum and Leea aequata were most active among the plants tested. This study thus can be further utilized to formulate the new antimicrobial agents to fight against Vibrio cholerae.
\end{abstract}

Key words: Nicobarese, TKPs (traditional knowledge practitioners), microorganisms.

\section{Introduction}

Morbidity and mortality, due to diarrhea, continue to be a major problem among children in many developing countries, including India [1]. Within these areas, Vibrio cholerae ( $V$. cholerae) followed by Escherichia coli are most prevalent bacterial pathogens [2]. V. cholerae is the causative agent of cholera, a life-threatening diarrheal disease that cause large pandemics, occur naturally in the environment and cause illness through contaminated food or water [3]. According to WHO (World Health Organization) reports, the annual acute diarrheal cases for $V$. cholerae infection were estimated more than a million people [4].

Systematic screening of plants used in traditional medicines could pave the way for the discovery of novel and effective compounds [5]. In the contemporary, alarming incidence of multidrug resistant strains of bacteria is being frequently noticed, and quite recently, this phenomenon has been critically analyzed and documented [6]. It indicated the necessity to continue the search for newer compounds to combat

Corresponding author: Paluru Vijayachari, M.D., research fields: antimicrobial agents and drug discovery. new infections.

The oral tradition is still prevalent among the tribes of India, where local communities in every ecosystem have discovered the medicinal uses of thousands of plants. Precious ancient knowledge of traditional methods is now limited to some of the closed communities particularly the remote tribal populations and is part of their culture, traditional beliefs, patterns of ecological adaptation for maintaining health and preventing disease and injury in its members [7].

Andaman and Nicobar Islands are a home to two distinct racial groups of primitive tribes' viz., Negretoes in the Andaman (Great Andamanese, Onges, Jarawas and Sentinelese) and Mongoloid in the Nicobar (Nicobarese and Shompens). More than 97\% of the tribal populations are Nicobarese, settled in different islands of Nicobar district. The Nicobarese are coastal dwellers and enjoy the vicinity of exuberant and verdant tropical forests [8].

Nicobarese are still living their customary way of life, especially those in Little Nicobar, Chowra and Teressa Islands, while the life in Nancowry, Kamorta, Katchal, Great Nicobar and Car Nicobar is on the verge of extinction due to modernization [9]. Tribal 
communities of Andaman and Nicobar Islands, especially the Nicobarese, depend on plant resources to prepare herbal medicines, for food, making household implements, as a sleeping mat and for fire. The former possess a great emporium of ethnobotanical wealth, as they are still isolated from the modern way of life and are still closer to nature.

Previous research articles report the results of a survey that was done based on ethnomedicinal practices among the Nicobarese tribes of the Andaman and Nicobar Islands [9-11], along with a bioassay tests for antimicrobial and antimalarial activities $[12,13]$. In the present study, a total of 18 plants were studied to determine and analyze the vibriocidal activity.

\section{Materials and Methods}

\subsection{Plant Material}

Plants were selected for this study based on their medicinal use, endemicity and availability to the TKPs during the field survey. Fresh plant parts were collected from the tribal villages of Car Nicobar Island. Table 1 provides the botanical name, family of the plant, local name (Nicobarese language) for 18 ethnomedicinal plants used for the present study.

\subsection{Extraction}

The leaves of plants were separately dried under shade, pulverized by a mechanical grinder to obtain a fine powder. Coarsely powdered leaves material were extracted by cold percolation method with 95\% methanol as solvent, for $72 \mathrm{~h}$ at room temperature. Extract was collected, filtered and the solvent was evaporated under reduced pressure in an evaporator at $40 \sim 45{ }^{\circ} \mathrm{C}$. The residues were stored at $4{ }^{\circ} \mathrm{C}$ for future use.

\subsection{Microorganism}

The microorganism Vibrio cholerae (MTCC (Microbial Type Culture Collection) 3906) used in this study was procured from Microbial Type Culture Collection, Chandigarh, India.

\subsection{Antimicrobial Susceptibility}

The agar well diffusion method was used to screen the vibriocidal activity [14]. The Mueller Hinton Agar plates were prepared by pouring $15 \mathrm{~mL}$ of molten media into sterile petriplates. To this $0.1 \%$ inoculum suspension of $V$. cholerae was swabbed uniformly, and allowed to dry for $5 \mathrm{~min}$. Wells were dug in agar plates

Table 1 Ethnomedicinal plants collected for antimicrobial activity [10].

\begin{tabular}{|c|c|c|c|}
\hline Serial No. & Botanical name & Family & Part used \\
\hline 1 & Abutilon indicum (L.) Sweet & Malvaceae & Leaves \\
\hline 2 & Ageratum conyzoides L. & Asteraceae & Leaves \\
\hline 3 & Annona squamosa L. & Annonaceae & Leaves \\
\hline 4 & Boesenbergia rotunda (L.) Mansf. & Zingiberaceae & Rhizome \\
\hline 5 & Cleome viscosa L. & Capparaceae & Leaves \\
\hline 6 & Ganophyllum falcatum Blume. & Sapindaceae & Leaves \\
\hline 7 & Glyptopetalum calocarpum (Kurz.) Prain & Celastraceae & Leaves \\
\hline 8 & Ipomea obscura (L.) Ker.- Gawl. & Convolvulaceae & Leaves \\
\hline 9 & Leea aequata $\mathrm{L}$. & Leeaceae & Leaves \\
\hline 10 & Leea indica (Burm.f.) Merr. & Leeaceae & Leaves \\
\hline 11 & Macranga peltata (Roxb.) Muell.-Arg. & Euphorbiaceae & Leaves \\
\hline 12 & Morinda citrifolia $\mathrm{L}$. & Rubiaceae & Leaves \\
\hline 13 & Moringa oleifera Lam. & Moringaceae & Leaves \\
\hline 14 & Premna corymbosa (Burm.f.) Rottl. et Willd. & Verbenaceae & Leaves \\
\hline 15 & Senna alata (L.) Roxb. & Caesapiniaceae & Leaves \\
\hline 16 & Tabernaemontana crispa Roxb. & Apocynaceae & Leaves \\
\hline 17 & Urena lobata $\mathrm{L}$ & Malvaceae & Leaves \\
\hline 18 & Wedelia biflora (L.) DC. & Asteraceae & Leaves \\
\hline
\end{tabular}


Table 2 Vibriocidal activity of the ethnomedicinal plants used by Nicobarese in Car Nicobar.

\begin{tabular}{lll}
\hline Botanical name & Inhibition zone $(\mathrm{mm})$ & Relative percentage inhibition (\%) \\
\hline A. indicum & $10.33 \pm 0.58$ & 59.61 \\
A. conyzoides & - & - \\
A. squamosa & - & - \\
B. rotunda & - & - \\
C. viscosa & - & - \\
G. falcatum & $13.67 \pm 0.58$ & 78.88 \\
G. calocarpum & $13.00 \pm 1.00$ & 75.01 \\
I. obscura & - & - \\
L. aequata & $13.33 \pm 0.58$ & 76.91 \\
L. indica & - & - \\
M. peltata & - & - \\
M. citrifolia & $18.00 \pm 1.00$ & 103.87 \\
M oleifera & - & - \\
P. corymbosa & - & - \\
S. alata & - & - \\
T. crispa & - & - \\
U. lobata & $10.00 \pm 1.00$ & 57.70 \\
W. biflora & $11.67 \pm 0.58$ & 67.34 \\
Gentamycin & $17.33 \pm 0.58$ & $\mathrm{NA}$ \\
\hline
\end{tabular}

"-" indicates no activity;

NA: not applicable.

with the help of sterile metallic borer (diameter $=6 \mathrm{~mm})$. $50 \mu \mathrm{L}$ of crude methanol extract of various plants were poured into the wells which were marked previously. The plates were kept for incubation at $37{ }^{\circ} \mathrm{C}$ aerobically for $18 \mathrm{~h}$. At the end of incubation period, inhibition zones formed around the disc were measured in millimeter, using a transparent scale.

\subsection{Determination of Relative Percentage Inhibition}

The relative percentage inhibition of the test extract with respect to positive control was calculated by using the following formula mentioned by Chander et al. [15] with minor modification.

Relative percentage inhibition of the test extract $=(X-Y) /(Z-Y) \times 100$

where:

$X$ : average inhibition zone of the test extract;

$Y$ : average inhibition zone of the solvent;

$Z$ : average inhibition zone of the standard.

\section{Results and Discussion}

In the assay, seven plant extracts showed vibriocidal activity against the strain used for the study. Among the plants screened Mcitrifoli citrifolia, Ganophyllum falcatum and Leea aequata were showed promising activity against tested microorganisms relative to standard drugs (Table 2).

The result of vibriocidal activity of crude extracts was compared with the positive control for evaluating their relative percentage inhibition (Table 2). The methanol extract of $M$. citrifolia exhibited maximum relative percentage inhibition (103.87\%) followed by G. falcatum (78.88\%), L. aequata (76.91\%), G. calocarpum $(75.01 \%)$, respectively.

Recent research reports clearly indicate that the $M$. citrifolia has immune modulatory properties, anti-cancer properties, anti-oxidant properties, anti-inflammatory activity and cardioprotective activity [16-20].

\section{Conclusions}

Further phytochemical studies are required to determine the bioactive compounds responsible for the vibriocidal activities of these species. The results also 
indicate that scientific studies carried out on medicinal plants having traditional claims of effectiveness might warrant fruitful results. These plants could serve as useful sources for new antimicrobial agents.

\section{Conflict of Interest}

The authors declare that they have no competing interests.

\section{Acknowledgments}

The authors acknowledge to the Indian Council of Medical Research (ICMR), New Delhi, India for providing financial grant for the study (Project No. Tribal/43/2008-ECD-II). Authors are grateful to the Tribal Councils, village captains and traditional knowledge providers of Nicobar group of Islands for providing us with their valuable ethnomedicine information and co-operation, without which this work would not have been possible. Authors are also thankful to Botanical Survey of India, Port Blair for their help in identification of plant specimens.

\section{References}

[1] Acharyya, S., Patra, A., and Bag, P. K. 2009. "Evaluation of the Antimicrobial Activity of Some Medicinal Plants against Enteric Bacteria with Particular Reference to Multi-drug Resistant Vibrio cholera." Trop. J. Pharm. Res. 8: 231-7.

[2] Salem, W., Leitnera, D. R., Zingla, F. G., Schratter, G., Prass, R., Goesslerd, W., et al. 2015. "Antibacterial Activity of Silver and Zinc Nanoparticles against Vibrio cholerae and Enterotoxic Escherichia coli." Intern. J. Med. Microbiol. 305: 85-95.

[3] Griffin, D. W., Lipp, E. K., Mclaughlin, M. R., and Rose, J. B. 2001. "Marine Recreation and Public Health Microbiology: Quest for the Iideal Indicator." BioScience 51: 817-25.

[4] WHO (World Health Organization). 2013. "Cholera 2012." Weekly Epidemiological Record 88: 321-36.

[5] Diallo, D., Hveem, B., Mahmoud, M. A., Betge, G., Paulsen, B. S., and Maiga, A. 1999. "An Ethnobotanical Survey of Herbal Drugs of Gourma District, Mali.” Pharm. Biol. 37: 80-91.

[6] Chethana, G. S., Hari, V. K. R., Mirzaei, F., and Gopinath, S. M. 2013. "Review on Multidrug Resistant Bacteria and Its Implication in Medical Sciences.” J. Biol. Sci. Opin. 1:
32-7.

[7] Verma, C., Bhatia, S., and Srivastava, S. 2010. "Traditional Medicine of the Nicobarese." Indian J. Trad. Knowl. 9: 779-85.

[8] Sinha, B. K., and Malick, K. C. 1995. Probable Potential Medicinal Plants of Andaman and Nicobar Islands. Port Blair: Botanical Survey of India.

[9] Chander, M. P., Kartick, C., and Vijayachari, P. 2015. "Herbal Medicine \& Healthcare Practices among Nicobarese of Nancowry Group of Islands-An Indigenous Tribe of Andaman \& Nicobar Islands.” Indian J. Med. Res. 141: 720-44.

[10] Chander, M. P., Kartick, C., Gangadhar, J., and Vijayachari, P. 2014. "Ethno Medicine and Healthcare Practices among Nicobarese of Car Nicobar-An Indigenous Tribe of Andaman and Nicobar Islands." $J$. Ethnopharmacol. 158: 18-24.

[11] Chander, M. P., Kartick, C., and Vijayachari, P. 2015. Medicinal Plants Used by the Nicobarese Inhabiting Little Nicobar Island of the Andaman and Nicobar Archipelago, India.” J. Altern. Complem. Med. 21: 373-9.

[12] Chander, M. P., and Vijayachari, P. 2016. In Vitro Antimicrobial and Anti-oxidant Potentials of Selected Medicinal Plants Used by the Indigenous Tribes of Andaman and Nicobar Islands, India." Bangladesh $J$. Pharmacol. 11: 330-2.

[13] Chander, M. P., Pillai, C. R., Sunish, I. P., and Vijayachari, P. 2016. "Antimalarial Efficacy of Six Medicinal Plants Used as a Traditional Medicine by the Nicobarese Tribes of Andaman and Nicobar Islands, India." Microb. Pathog. 96: 85-8.

[14] Rojas, J. J., Ochoa, V. J., Ocampo, S. A., and Munoz, J. F. 2006. "Screening for Antimicrobial Activity of Ten Medicinal Plants Used in Colombian Folkloric Medicine: A Possible Alternative in the Treatment of Non-nosocomial Infections." BMC Complement. Altern. Med. 6 (2): 1-6.

[15] Chander, M. P., Sachithanandam, V., and Vijayachari, P. 2014. "Antimicrobial and Haemolytic Activity of Seaweed Padina gymnospora from South Andaman, Andaman and Nicobar Islands of India." Intern. J. Curr. Microbiol. Appl. Sci. 3: 364-9.

[16] Wang, M. Y., and Su, C. 2001. "Cancer Preventive Effect of Morinda citrifolia (Noni)." Ann. New York Acad. Sci. 952: 161-8.

[17] Mohd, Z., Abdul-Hamid, A., and Osman, A. 2001. "Antioxidative Activity Extracts from Mengkudu (Morinda citrifolia L.) Root, Fruit and Leaf." Food Chem. 78: 227-31.

[18] McKoy, M. L. G., Thomas, E. A., and Simon, O. R. 2002. "Preliminary Investigation of the Anti-inflammatory Properties of an Aqueous Extract from Morinda citrifolia 
(Noni)." Pharmacol. Soc. 45: 76-8.

[19] Wang, M. Y., West, B., Jensen, C. J., Nowicki, D., Su, C., Palu, A. K., and Anderson, G. 2002. "Morinda citrifolia (Noni): A Literature Review and Recent Advances in Noni Research." Acta Pharmacol. Sinica. 23:
1127-41.

[20] Saludes, J. P., Garson, J. M., Franzblau, S. G., and Aguinaldo, A. M. 2002. "Anti-tubercular Constituents from the Hexane Fraction of Morinda citrifolia L. (Rubiaceae)." Phyto. Res. 16: 683-5. 